\title{
Climate change scenarios at Austrian National Forest Inventory sites
}

\author{
C. Matulla ${ }^{1, *}$, N. Groll ${ }^{1}$, H. Kromp-Kolb ${ }^{1}$, H. Scheifinger ${ }^{2}$, \\ M. J. Lexer ${ }^{3}$, M. Widmann ${ }^{4}$ \\ ${ }^{1}$ Institute of Meteorology and Physics, University for Agricultural Sciences, Türkenschanzstrasse 18, Vienna, Austria \\ ${ }^{2}$ Central Institute for Meteorology and Geodynamics, Hohe Warte 38, Vienna, Austria \\ ${ }^{3}$ Institute of Silviculture, University for Agricultural Sciences, Peter-Jordanstr. 70, Vienna, Austria \\ ${ }^{4}$ Institute for Coastal Research, GKSS Research Centre, Max-Planck-Straße, 21502 Geesthacht, Germany
}

\begin{abstract}
Regional risk assessments for the potential effects of climate change rely on plausible small-scale climate change scenario data. To bridge the gap between the coarse scale of general circulation models and the local scale of approximately 11000 sample sites of the Austrian National Forest Inventory (AFI), a seasonally stratified statistical downscaling procedure was applied to a control run and 2 transient experiments of ECHAM4/OPYC3, which are based on the trace gas only or trace gas plus sulphate scenario IPCC IS92a. We fitted multiple linear regression (MLR) models for the micro-scale monthly precipitation and temperature for each AFI point. The meteorological data at the AFI sites were obtained by interpolation of measurements from the dense network of Austrian weather stations for the period 1961-1995. The macro-scale predictors were principal components of monthly NCEP/NCAR reanalysis data 850 and $700 \mathrm{hPa}$ geopotential height, $850 \mathrm{hPa}$ temperature and $700 \mathrm{hPa}$ relative humidity). The results show spatial and temporal heterogeneity for both temperature and precipitation. In case of temperature MLR leads to increases from +1.4 to $+4.0^{\circ} \mathrm{C}$ (trace gas only integration) and from +1.1 to $+2.9^{\circ} \mathrm{C}$ (trace gas plus sulphate integration) for a period of about 55 yr relative to the 1961-1995 climatology. The regionalized precipitation changes are both negative and positive. Values range from -44 to $+26 \%$ (trace gas only integration) and from -29 to $+26 \%$ (trace gas plus sulphate integration). As expected, the explained variability for temperature was higher than for precipitation and depended on the season. From a validation experiment for model calibration we conclude that MLR shows reliable results for temperature. Even in the case of precipitation the method seems to yield plausible results. Both temperature and precipitation were better reproduced for winter than for summer.
\end{abstract}

KEY WORDS: Climate change - Downscaling $\cdot$ Principal component analysis $\cdot$ Multiple regression · Forest inventory

Resale or republication not permitted without written consent of the publisher

\section{INTRODUCTION}

The possibility of anthropogenically induced climate change through an increase in trace gas concentrations in the atmosphere has led to the development of various tools to investigate future climatic changes. General circulation models (GCMs) constitute the main instrument to analyse possible changes in the global climate system

*E-mail: matulla@ap.univie.ac.at regarding atmospheric and oceanic features at rather coarse scales (Roeckner et al. 1996). Computational limitations are the main reason why the spatial resolution of GCMs is limited to a few hundred kilometers. However, impact assessments of the effects of climatic changes on terrestrial ecosystems require climate change scenario data at much finer scales (Kienast et al. 1996, Lindner et al. 1997, Lexer et al. 2000). Moreover, it is estimated that the skillful scale of GCMs is about 8 times the grid scale. Output on spatial scales smaller than the skillful scale should not be interpreted (Joannesson et al. 1995). 
GCMs are suitable to reproduce the large-scale behaviour of climatic parameters. Phenomena with a wavelength below the skillful scale, such as effects caused by steep topography, cumulus cloud processes or boundary layer processes over heterogeneous surfaces, cannot be simulated satisfactorily (Grotch \& MacCracken 1991). During the last few years a common understanding has evolved that scenario output of GCMs should not be used directly for climate change impact studies at regional and local scales (von Storch et al. 1993).

In order to generate climate data at these small scales, the output from GCMs has to be regionalized. Up to now a number of different downscaling techniques have been developed which relate local-scale climate variables to larger-scale variability of the atmosphere. A tempting but usually inadequate strategy is to interpolate GCM scenario data from the coarse grid to a grid with a high resolution (Cohen \& Allsopp 1988, Smith 1991). Among the more advanced techniques, 3 general approaches can be distinguished (see, for example, Fuentes \& Heimann 1996): (1) process-based techniques with regional circulation models (RCM) nested into a GCM (Giorgi 1990, Grotch \& MacCracken 1991, Giorgi et al. 1994); (2) empirical techniques using transfer functions between the scales (Wigley et al. 1990, von Storch et al. 1993, Zorita et al. 1995); and (3) statistical-dynamical downscaling through statistics derived for large-scale weather types, which are multi-day episodes grouped into a number of classes. To simulate the regional evolution of weather, a regional model is applied to the most representative episodes in each class. (Frey-Buness et al. 1995, Fuentes \& Heimann 2000).

The procedure used in the present study belongs to group (2). In principle group (1) should generate the most reliable regional results, because topography, land-use patterns and other geographical features can be taken into account based on physical processes simulated with a high resolution. However, this strategy is in an early phase of development, requires detailed surface data, and depends on high-end computing resources. Empirical and semi-empirical relationships offer an attractive approach at significantly lower computing costs (Hewitson \& Crane 1996). However, empirical techniques rely on the stability of the relationship between the predictors and the predictand, which is not necessarily the case in a climate change scenario. In any case scenarios produced by both dynamical and statistical downscaling approaches are ultimately constrained by the realism of the boundary forcing of the host GCM.

Our general objective is to provide a transient climate change scenario of monthly temperature and precipitation data for a large set of sample points of the
Austrian National Forest Inventory (AFI), which in turn can be used for an assessment of potential climate change effects on Austrian forests.

To accomplish this task we regionalized the scenario output of the GCM ECHAM4/OPYC3 (Roeckner et al. 1996) by means of principal component analysis (PCA) (Preisendorfer 1988) of large-scale atmospheric fields and subsequent multiple linear regression (MLR).

\section{DATA}

We used the following data sets for our statistical downscaling procedure:

For model fitting we used monthly mean temperature, relative humidity and geopotential height at 3 pressure levels $(850,700$ and $500 \mathrm{hPa}$ ) from 1961 to 1995, taken from the National Center for Environmental Prediction (NCEP) and the National Center for Atmospheric Research (NCAR) reanalysis (Kalnay et al. 1996) (resolution is T62). As the alpine climate is strongly related to processes over the North Atlantic Ocean (Wanner et al. 1997), we considered a section from $50^{\circ} \mathrm{W}$ to $30^{\circ} \mathrm{E}$ and $35^{\circ}$ to $65^{\circ} \mathrm{N}$.

On the regional scale we spatially interpolated monthly mean temperature and precipitation for the period 1961-1995 from the dense network of Austrian weather stations to approximately 11000 sample points of the AFI (Scheifinger \& Kromp-Kolb 1999). The AFI samples site and stand data of Austrian forests on a regular grid of about $3.8 \times 3.8 \mathrm{~km}$ (FBVA 1995). For the sake of temperature interpolation Austria was divided into 8 subregions. The subregions should comprise areas of similar potential inversion structure, for instance the main Alpine valleys and basins. The size of the regions should be as large as necessary to guarantee a sufficient amount of stations for a reliable relationship between temperature and elevation. During the cold season inversions are frequent, which require a polynomial fit of the relationship between temperature and elevation. Nevertheless, residuals are much higher during the cold season and range up to $2{ }^{\circ} \mathrm{C}$ greater than during the warm season, with residuals generally $<1^{\circ} \mathrm{C}$. The interpolation procedure for precipitation is based on mean monthly slopes for the relationship between precipitation and station elevation over the entire region, which are calculated by linear regression. At each of the points monthly precipitation values are interpolated by means of inverse distance weighting. The relationship between monthly precipitation sums and station elevation is fitted by linear regression, making use of the long-term climatological monthly slope values. The RMSE for monthly time series ranges from 10 to $40 \mathrm{~mm}$, with higher values over the northern slopes of the Alps. 
As predictors for the small-scale scenarios, we used output from the coupled atmosphere-ocean GCM ECHAM4/OPYC3 (Roeckner et al. 1996) from the Deutsches Klimarechenzentrum (DKRZ; German Climate Computing Center) at a T42 spatial resolution $\left(2.8^{\circ} \times 2.8^{\circ}\right)$. The same large-scale variables, regions and pressure levels that were taken into account for model fitting were selected, and the data were interpolated to the NCEP/NCAR reanalysis grid. Three runs were analysed: (1) a 300 yr unforced control simulation with trace gas concentrations kept at 1990 levels; (2) A greenhouse gas only forced experiment $\left(\mathrm{CO}_{2}\right)$ using historical greenhouse gas forcing from 1860 to 1990 followed by a $1 \%$ annual increase in radiative forcing from 1990 to 2099; and (3) a greenhouse gas plus sulphate integration $\left(\mathrm{CO}_{2}+\mathrm{SO}_{4}\right.$ aerosols $)$ from 1990 to 2049. These scenarios are in accordance with the IS92a emission scenario of the Intergovernmental Panel on Climate Change (IPCC) (IPCC 1992). Meteorological variables and pressure levels are the same as for the NCAR reanalysis data.

\section{METHODS}

\subsection{The statistical downscaling procedure}

According to (Hewitson \& Crane 1996) typical steps in statistical downscaling are:

(1) Identification of a set of macro-scale variables, $X_{i}$, that do not only represent the variability of the largescale field distribution well, but are also related to the local predictands, $Y_{j}$ (micro-scale variables); (2) Derivation of a statistical relation between macro- and micro-scale variables $X_{i}$ and $Y_{j}$ by means of multiple regression analysis; (3) Validation of the statistical relation with independent data; (4) Extraction of the predictors $X_{i}$ from a GCM experiment and calculation of an estimate for $Y_{j}$ at the local scale.

\subsection{PCA}

Lorenz (1956) introduced a statistical method using eigenfunctions to reduce large datasets without losing much information about the variance of the data. Eigenvector techniques follow different modes of decomposition leading to distinct types of dispersion matrices and consequently to advantages and disadvantages for different kinds of objectives (Ehrendorfer 1987, Preisendorfer 1988, Yarnal 1993). In this work PCA in S-mode is used. PCA in S-mode describes a time series of spatial fields (e.g. $850 \mathrm{hPa}$ geopotential heights) as a linear combination of certain basis fields (Eq. 1), which are called empirical orthogonal functions (EOFs). The EOFs $\left(\mathbf{e}_{m}\right)$ represent the dominant patterns of spatial variability in order of decreasing importance, and therefore an approximate expansion

$$
\mathbf{f}_{n} \approx \sum_{m=1}^{K} p c_{n m} \mathbf{e}_{m}
$$

using only the first $K$ EOFs is the best approximation (in a least-squares sense) to the data, $\mathbf{f}_{n}$, that can be obtained with any $K$ fields. The time dependence of the spatial fields $\mathbf{f}$ and of the time expansion coefficients $p c_{n m}$ which are called principal components (PCs), is included in the index $n$. Here $\mathbf{f}_{n}$ represent the effective NCEP/NCAR data minus the seasonal cycle (the $35 \mathrm{yr}$ monthly means). The description of $\mathbf{f}_{n}$ in terms of the PCs reduces drastically the number of variables needed to describe the data on an approximate level. The EOFs are defined by the variational problem

$$
\frac{1}{N} \sum_{i=1}^{N}\left\langle\mathbf{f}_{i} \mid \mathbf{e}_{m}\right\rangle^{2}=\left(\mathbf{e}_{m}^{T} \mathrm{Re}_{m}\right) \stackrel{!}{=} \text { Min. }
$$

where $N$ denotes the number of time steps and $\mathrm{R}$ is the covariance matrix. In addition, the EOFs are subject to the orthonormality condition

$$
\left\langle\mathbf{e}_{i} \mid \mathbf{e}_{j}\right\rangle=\delta_{i, j}
$$

It can be shown that the EOFs are the normalized eigenvectors of the covariance matrix. The largescale field contains 429 gridpoints in our analysis domain, and the monthly series from 1961 to 1995 include 420 time steps. According to Ehrendorfer (1987) such a setup is appropriate for obtaining the required degree of statistical significance for the EOFs and PCs.

\subsection{Multiple linear regression}

The MLR model relates the micro-scale variables the monthly precipitation totals and temperature means at the AFI sample points $\left(Y_{i}\right)$ - to the PCs $\left(X_{i}\right)$ of the macro-scale variables via the regression coefficients $\left(b_{i}\right)$ :

$$
Y_{i, j}=b_{i, 0}+\sum_{k=1}^{K} b_{i, k} X_{k, j}
$$

where $i$ and $j$ distinguish points and time steps, respectively. $k$ runs from 1 up to the number of predictors taken into account (in the present study 10 in case of temperature and 20 in case of precipitation). 


\section{RESULTS}

\subsection{EOFs}

Fig. 1 shows the 5 leading EOFs of winter (DJF) monthly-mean geopotential height and temperature over the North Atlantic and Europe at the $850 \mathrm{hPa}$ level (Z850 and T850). Analogous EOFs were calculated for the other seasons. The associated PCs were then used as predictors for the MLR model. For brevity only the winter EOFs are shown.

In winter the first 5 Z850 EOFs explain more than $90 \%$ of the total variance. The dipole structure of EOF1 with centers over Iceland and the Azores is similar to the North Atlantic oscillation (NAO) pattern (Lamb \& Peppler 1987), and consequently PC1 is highly correlated (0.87) with Hurrell's NAO index (Hurrell 1995), which is defined as the normalized Lisbon (Portugal) minus Stykkisholmur (Iceland) sea-level pressure (SLP) anomaly. EOF2 is a monopole pattern with the largest loadings over the Atlantic around $55^{\circ} \mathrm{N}$, where EOF1 has loadings close to zero, and thus it explains only very little of the local SLP variability. Since PCs are temporally uncorrelated, the SLP variability in this region is only weakly correlated to the NAO. Both EOFs are centered over the western part of the domain, which indicates a west-east decrease in the variance of geopotential height. The first 2 EOFs explain a similar fraction of variance, and therefore the distinction between these 2 EOFs is likely not to remain if the data or domain were slightly altered. The robust structure is the 2-dimensional subspace spanned by EOF1 and EOF2, which explains $66.6 \%$ of the total variance and describes the variability in the entire western part of the domain. EOF3 mainly captures the variability over the North Sea and north-eastern Europe, which is the exit region of the North Atlantic storm track. EOF4 and EOF5 are not clearly localized, and their quadrupole structures explain further details of the field.

The first 5 T850 EOFs explain about $85 \%$ of the variance in the wintertime temperature. The first T850 EOF describes the temperature difference between the north-eastern Atlantic and Central Europe. Since a strong NAO is associated with warming (cooling) over Europe (the north-eastern Atlantic), the T850 and Z850 PC1s are positively correlated (0.39). As southwesterly flow of the type associated with Z850 EOF2 warms Europe as well, the T850 PC1 is even more clearly correlated with the Z850 PC2 (0.66). T850 EOF2 describes zonal temperature gradients over Europe along with a temperature anomaly over the Atlantic centered around $45^{\circ} \mathrm{N}$. T850 PC2 has the strongest correlation with the NAO-type Z850 PC1 (-0.73), which shows not only that in winter positive (negative) NAO phases tend to warm (cool) Europe, but also that they lead to strong (weak) zonal temperature gradients. In other words, the NAO-induced temperature variability is strongest in the western parts of Europe. In addition, this correlation suggests a cold-high pressure, warm-low pressure relationship over the mid-latitude Atlantic in winter. EOF3 represents the temperature difference between the North Atlantic and south-eastern Europe and explains a similar fraction of the total variance as EOF2, which means that the distinction between the 2 EOFs is not robust. T850 PC3 is moderately correlated with all 3 leading Z850 PCs $(0.37,-0.49,-0.54)$. EOF4 approximately describes the average temperature south of $60^{\circ} \mathrm{N}$, and PC4 is highly correlated with the Z850 PC4 (-0.72). This is understandable since Z850 PC4 will be low (high) in blocking (zonal) situations over western Europe, which tend to cool (warm) the entire area. EOF5 is a tripole pattern whose PC is not clearly correlated to any of the leading Z850 PCs.

Similar patterns and relationships were obtained for the other seasons. In summer, for instance, Z850 EOF1 describes the geopotential height field over northwestern Europe (monopole centered over the British Isles). As could be expected, positive (negative) T850 anomalies over the same region (T850 EOF1) are associated with high (low) Z850, which is indicated by a high correlation (0.76) of the respective PCs. An NAOtype Z850 anomaly emerges during summer as Z850 EOF2 (correlation with the NAO index is 0.77). This pattern shows low pressure over Iceland in conjunction with a blocking situation over central Europe. It is associated with a warm anomaly over south-western Europe described by T850 EOF2 (correlation of PCs is 0.68), whose exact position is controlled by T850 EOF3 (correlation of PC3 with Z850 PC2 is 0.49). These correlations seem to be due to a modulation of the advection of subtropical air on the south-western side of a central European high-pressure system.

In the cases where physically plausible correlations of the Z850 and T850 were found, the T850 EOFs can be partly understood as advection patterns of Z850 EOFs. Limitations of this interpretation are given by the fact that the squared correlations, which are the fraction of variance in the T850 PCs that can be linearly explained by a given Z850 PC, are at the most about 0.5 and the fact that in many cases several Z850 PCs show a substantial correlation with a given T850 PC (only the most important correlations were given above).

\subsection{Calibrating models for temperature and precipitation}

To simulate precipitation changes for the Susquehanna Basin, Crane \& Hewitson (1998) utilized relative 

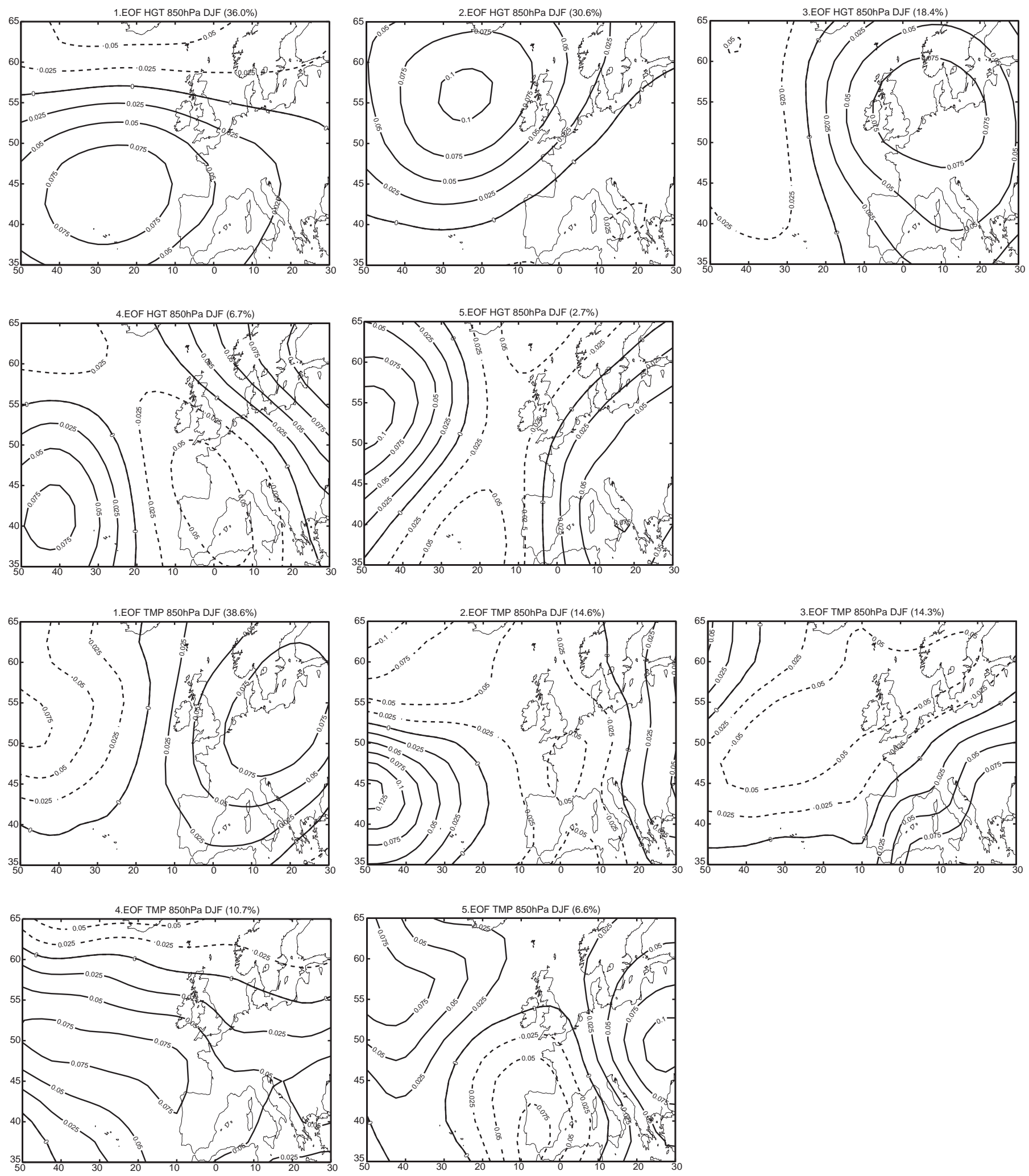

Fig. 1. Leading winter (DJF) EOFs of 850hPa geopotential height (upper 5 panels) and $850 \mathrm{hPa}$ (lower 5 panels) from the NCEP/NCAR reanalysis (geographical sector from $50^{\circ} \mathrm{E}$ to $30^{\circ} \mathrm{W}$ and $35^{\circ}$ to $65^{\circ} \mathrm{N}$. The explained variance is shown in the panel headers 
humidity and geopotential data. Wigley et al. (1990) explored the relationships between local temperature and precipitation and large-scale climate variables in Oregon. They found that most of the variance explained arises from the area average of the variable which is the predictand. In the present study temperature and geopotential height (relative humidity and geopotential height) are utilized as predictor variables for local temperature (precipitation).

There are different criteria to select the number of eigenvectors which separates the signal from the noise (see, for example, Compagnucci \& Salles 1997 and references therein). We used a visual approach via the LEV (log-eigenvalues) diagram. This is the so-called scree test, in which a break in a plot of the logarithm of the eigenvalue versus eigennumber indicates the appropriate number of required EOFs. Fig. 2 contains such plots for geopotential height, temperature and relative humidity.

In the upper 3 panels there is a gap between the logarithm of the fifth and sixth eigenvalue. This gap indicates a significant drop in the ability to describe the variability of the field distribution. Such a clear signal cannot be found for relative humidity. In the case of geopotential height and temperature the first 5 eigenvectors are sufficient to explain approximately 90 and $75 \%$ of the variance respectively, whereas for relative humidity 15 EOFs are necessary to achieve approximately the same result. Therefore we take into account the leading 5 geopotential height and temperature EOFs and the leading 15 relative humidity EOFs. In the case of temperature (precipitation) we investigated the composition of 5 temperature and geopotential height PCs (15 relative humidity and 5 geopotential height PCs) at the 3 pressure levels. In order to find the best composition, we calculated the correlation between measured and modeled time series at the AFI points.

In a first setup the complete time series (1 at every AFI sample point) of $35 \mathrm{yr}$ is used for model fitting (Expt A). Cross validation is discussed in the next section. Best results in explaining micro-scale temperatures were obtained with $850 \mathrm{hPa}$ geopotential height and temperature as macro-scale predictors. The models explain between $58 \%(56 \%)$ and $91 \%$ (80\%) of the variance during the winter (summer) season. Variability of micro-scale monthly precipitation totals can be explained best by geopotential height and relative humidity at $700 \mathrm{hPa}$. However, the proportion of explained variance is lower-26\% (19\%) to $75 \%$ (64\%) during winter (summer) - than in the temperature case. Fig. 3 shows the spatial distribution of explained variance in the micro-scale variables over Austria, and Table 1 contains statistical values for the 2 seasons.
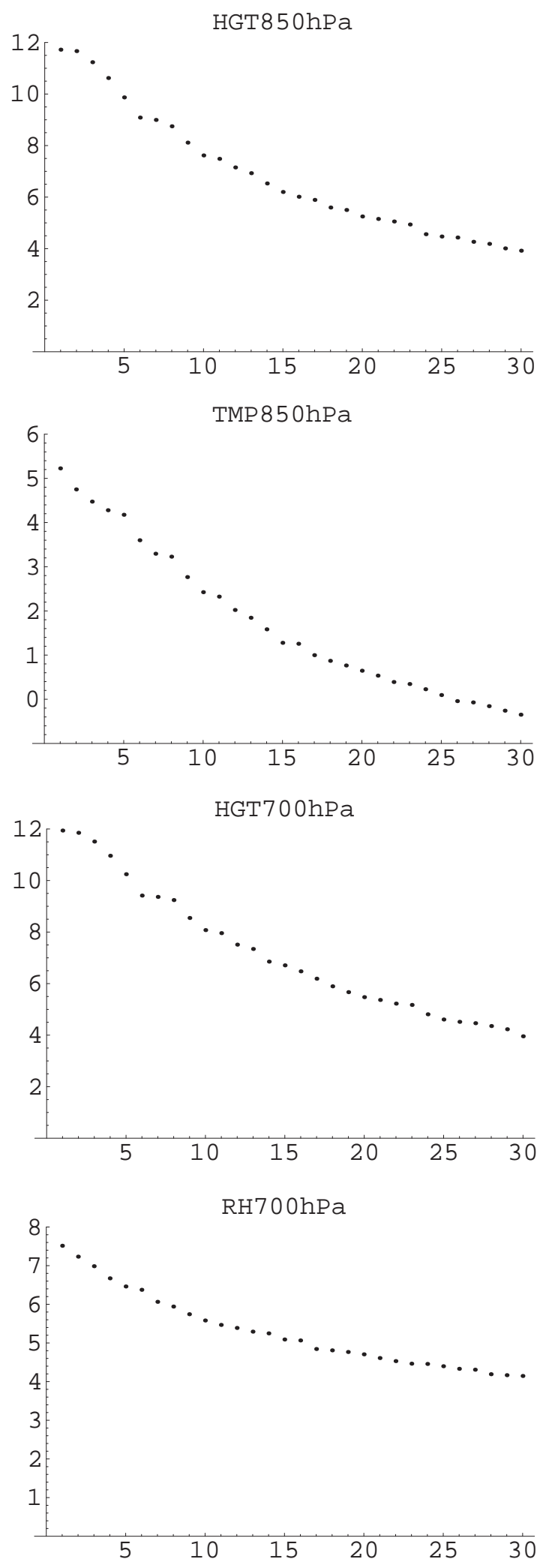

Fig. 2. Plots of the logarithm of the eigenvalue vs the eigennumber. HGT: geopotential height; TMP: temperature; $\mathrm{RH}$ : relative humidity 
The blue areas in Fig. 3 show a low correlation coefficient. The central Alpine chain and parts of the Eastern lowlands of Austria show in winter significantly lower $\mathrm{r}^{2}$ values than the areas north and south of this strip. In summer the low $\mathrm{r}^{2}$ strips seem very much enlarged. The high precipitation region and the high $\mathrm{r}^{2}$ area overlap to a large degree in winter, when disturbances originating over the Atlantic or the Mediterranean are the dominant precipitation sources for the Alps.

\subsection{Cross-validation}

In order to figure out how the regression models perform with independent data, the same procedure was applied using different periods for fitting and validating. In the validation sample the regressed anomalies are compared with the true anomalies at the 11000 AFI points. The relatively short period (35 yr) of data on the regional scale was split in 2 setups: (1) in periods from 1961-1985 and 1986-1995 respectively (Expt B), and (2) in periods 1961-1978 and 1979-1995 (Expt C). The result of these tests (mean value, minimum, maximum and standard deviation of the squared Pearson correlation coefficient) and the significance level $t$ at which the null hypothesis of zero correlation is rejected are summarized in Tables $1 \& 2$.

Expt A was already described in Section 4.1. In winter, correlation coefficients $r$ for temperature and precipitation are between 0.76 and 0.95 (explaining 58 to $91 \%$ of the month-to-month variability) and between 0.51 and 0.87 (explaining 26 to $75 \%$ ) respectively. The spatial distribution of $\mathrm{r}^{2}$ is shown in Fig. 3. The correlation at each AFI point is, for both temperature and precipitation, significant at the $99 \%$ level. In summer, the model performance declines.

In Expt B we restrict the fitting period to $25 \mathrm{yr}$ and calculate the correlation coefficients during the complementary validation period. Pearson correlation coefficients remain remarkably high in the case of temperature. Again, all coefficients are significant at the $99 \%$ level. In the case of precipitation a decrease in $r$ occurs and values of $r^{2}$ greater then $0.21(0.13)$ are significant at the $99 \%$ (95\%) level. In winter $24 \%(10 \%)$ of the AFI points show values for $\mathrm{r}^{2}$ of less then $0.21(0.13)$.

In Expt $\mathrm{C}$ the number of time steps for model fitting was further reduced to approximately $50 \%$ of the total period. In the case of temperature the regression model yields results closely related to those of Expts A and B (all values are significant at $99 \%$ ). Compared with the results of Expt $B$ the performance of the models for precipitation decreases further. Values of $\mathrm{r}^{2}$ greater than $0.13(0.08)$ are significant at $99 \%(95 \%)$. In winter the amount of models with $\mathrm{r}^{2}$ less then 0.08 is about $15 \%$.

The different behaviour of $\mathrm{r}^{2}$ may indicate that the performance of the models (1) saturates relatively quickly for temperature, (2) requires a longer fitting period for precipitation and (3) could be affected by the lack of local data and the necessity of the interpolation procedure over the complex Alpine terrain.

The ranges of values are similar to those obtained in other downscaling studies for Alpine precipitation (e.g. Gyalistras et al. 1994). Fischlin \& Gyalistras (1997) used CCA (canonical correlation analysis) and obtained correlation coefficients representative for regions. Their results are comparable to our areas with $\mathrm{r}^{2}$ between 0.3 and 0.52. Widmann (1996) worked with a weather classification by Schuepp and PCs and obtained similar results. In any experiment the model performs better in winter than in summer, and in case of precipitation the difference is considerable.

\subsection{Regionalized temperature and precipitation data}

The strategy applied to the NCEP/NCAR data was used to transfer macro-scale climatological variables of future periods (as simulated by ECHAM4/OPYC3

Table 1. Statistical distribution of the correlation coefficient related to the winter season (DJF)

\begin{tabular}{|lcccccrr|}
\hline \multirow{2}{*}{ Expt } & \multirow{2}{*}{ Predictand } & \multicolumn{6}{c|}{ Squared correlation coefficient $\mathrm{r}^{2}$} \\
\cline { 3 - 8 } & & Min & Max & Mean & SD & Sign. level & Fulfilled by \\
\hline \multirow{3}{*}{ A } & Temp & 0.58 & 0.91 & 0.79 & 0.04 & $99 \%$ & $100 \%$ \\
& Prec & 0.26 & 0.75 & 0.54 & 0.07 & $99 \%$ & $100 \%$ \\
B & Temp & 0.64 & 0.92 & 0.84 & 0.03 & $99 \%$ & $100 \%$ \\
& Prec & 0.02 & 0.70 & 0.32 & 0.14 & $99 / 95 \%$ & $76 / 90 \%$ \\
C & Temp & 0.55 & 0.92 & 0.81 & 0.03 & $99 \%$ & $100 \%$ \\
& Prec & 0.02 & 0.57 & 0.20 & 0.12 & $99 / 95 \%$ & $70 / 85 \%$ \\
\hline
\end{tabular}

Table 2. Statistical distribution of the correlation coefficient related to the summer season (JJA)

\begin{tabular}{|lcrrrrrr|}
\hline \multirow{2}{*}{ Expt } & Predictand & \multicolumn{6}{c}{ Squared correlation coefficient $\mathrm{r}^{2}$} \\
\cline { 3 - 8 } & & Min & Max & Mean & SD & Sign. level & Fulfilled by \\
\hline \multirow{2}{*}{ A } & Temp & 0.56 & 0.80 & 0.70 & 0.02 & $99 \%$ & $100 \%$ \\
& Prec & 0.19 & 0.64 & 0.33 & 0.06 & $99 \%$ & $100 \%$ \\
B & Temp & 0.67 & 0.85 & 0.79 & 0.02 & $99 \%$ & $100 \%$ \\
& Prec & 0.00 & 0.55 & 0.08 & 0.08 & $99 / 95 \%$ & $5 / 19 \%$ \\
C & Temp & 0.55 & 0.81 & 0.72 & 0.02 & $99 \%$ & $100 \%$ \\
& Prec & 0.00 & 0.50 & 0.07 & 0.07 & $99 / 95 \%$ & $14 / 37 \%$ \\
\hline
\end{tabular}



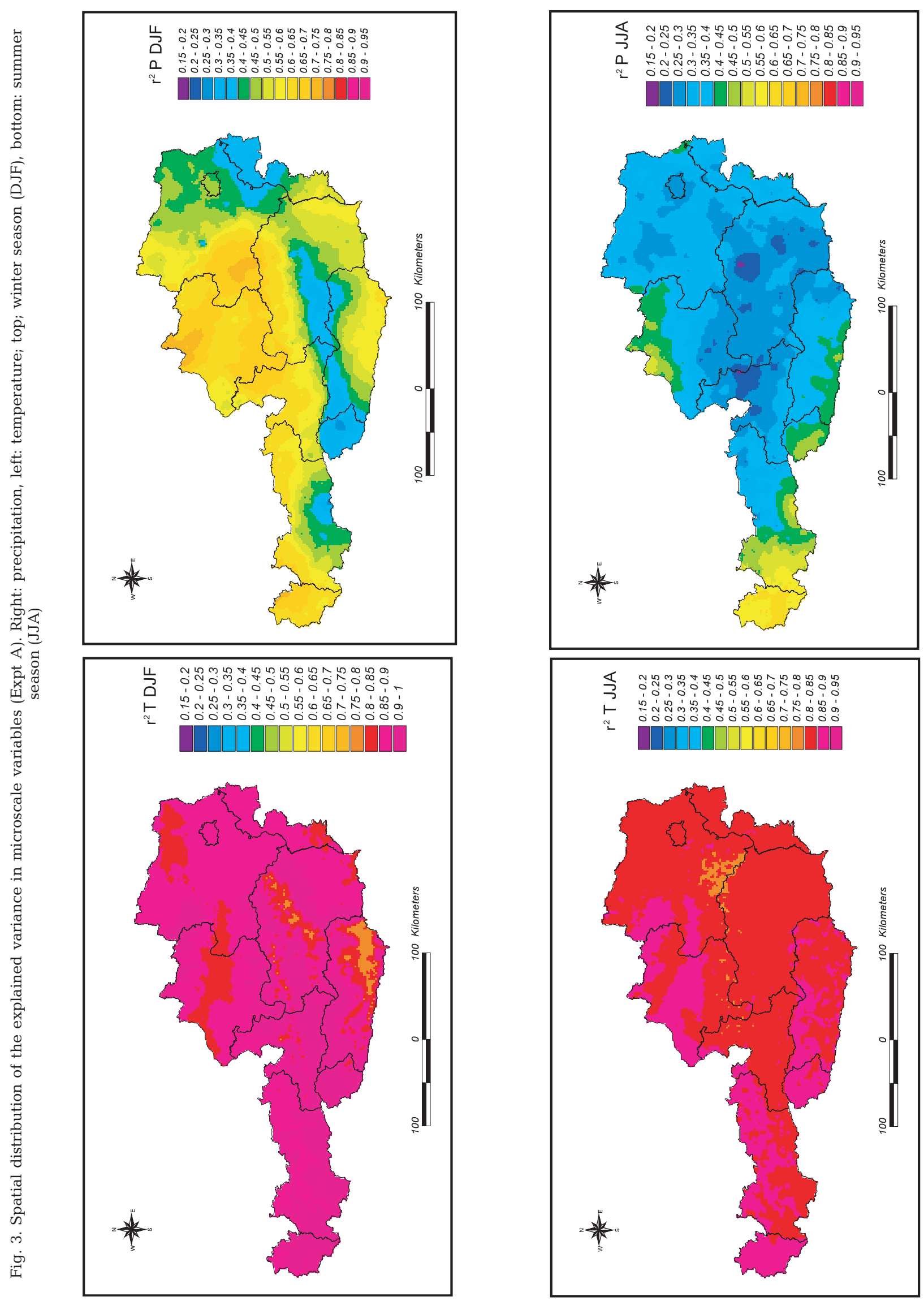
[Roeckner et al. 1996] under a control run and 2 IS92a scenarios) to the inventory sites at the microscale. We utilized the greenhouse gas only experiment $\left(\mathrm{CO}_{2}\right)$ from 2000 to 2050 and the greenhouse gas plus aerosols scenario run $\left(\mathrm{CO}_{2}+\mathrm{SO}_{4}\right.$ aerosols $)$ from 2000 to 2049 (because more data are not available). For this task the MLR models were calibrated with the whole $35 \mathrm{yr}$ time series at each inventory site (Expt A). The PCs which were used as predictors to generate the scenarios were calculated by projecting the ECHAM4/OPYC3 anomalies onto the NCEP/ NCAR-EOFs. The anomalies were derived by substracting climatological monthly means (calculated by the control experiment) from the effective values of the scenario run. This procedure resulted in time series for temperature and precipitation at each inventory plot. Tables 3 \& 4 show the differences between the 1961-1995 climatology and the periods 2016-2050 (CO $)_{2}$ and 2015-2049 $\left(\mathrm{CO}_{2}+\mathrm{SO}_{4}\right.$ aerosols) respectively and the related seasonal statistics considered in this study. The values represent means over all AFI points.

Figs. $4 \& 5$ show the spatial distribution of winter and summer mean temperature and precipitation anomalies respectively relative to the observed climatology (1961-1995) for the $\left(\mathrm{CO}_{2}\right)$ and the $\left(\mathrm{CO}_{2}+\mathrm{SO}_{4}\right.$ aerosols $)$ experiment. The panels indicate that, according to our downscaling approach, the local-scale response of seasonal mean temperature to global warming is heterogeneous in space and depends on the seasons. Please note that the sample points of the AFI are restricted to the forested area. Thus, the spatial interpolation in areas above the timberline as well as in the most eastern parts of Austria with the lowest share of forests should be treated with caution.

Table 3. Regional response to the IS92a-'greenhouse gas only'-scenario relative to the 1961-1995 climatology. Related seasonal statistics of the variables considered in this study winter (DJF), spring (MAM), summer (JJA) and autumn $(\mathrm{SON})$

\begin{tabular}{|lrrrr|}
\hline $0.1^{\circ} \mathrm{C}$ & \multicolumn{4}{c|}{ Temperature $\left(\mathrm{CO}_{2}\right.$-Exp. $)$} \\
& DJF & MAM & JJA & SON \\
\hline Min & 25.7 & 23.8 & 14.1 & 23.0 \\
Max & 39.8 & 34.6 & 29.2 & 40.1 \\
Mean & 32.0 & 28.4 & 20.3 & 28.4 \\
SD & 21.0 & 14.4 & 9.3 & 13.6 \\
\hline \multicolumn{5}{c}{ Precipitation $\left(\mathrm{CO}_{2}\right.$-Exp. $)$} \\
\hline \% & \multicolumn{5}{c}{ MAM } & JJA & SON \\
\hline Min & -28.6 & -34.0 & -44.3 & -32.7 \\
Max & 15.9 & 11.9 & 25.5 & 22.1 \\
Mean & -4.5 & -10.5 & -2.8 & -5.8 \\
SD & 50.6 & 33.2 & 20.7 & 38.6 \\
\hline
\end{tabular}

The main results are:

(1) The modelled local temperature increase (see Fig. 4) lies in the range given by the ECHAM4/OPYC3 experiments (northern hemisphere, especially Europe).

(2) It is heterogeneous in space and depends on the season.

(3) It is largest for the greenhouse only scenario, during winter (DJF) and in the northern and most western parts of Austria.

(4) In general there is a stronger warming with increasing elevation.

(5) The spatial distribution of the regionalized $\left(\mathrm{CO}_{2}\right)$ scenario looks quite similar to the $\left(\mathrm{CO}_{2}+\mathrm{SO}_{4}\right.$ aerosols $)$ experiment, but there is about 1 degree difference in magnitude.

(6) In the case of precipitation (Fig. 5) our results show decreases as well as increases in seasonal precipitation, while temperature is characterized by a general increase.

(7) As in the case of temperature the patterns are related.

(8) The quantitative change of precipitation sums appears substantial, up to a $25 \%$ increase and a $44 \%$ decrease.

(9) Precipitation scenarios reveal 2 contiguous areas of precipitation increase and decrease, which seem to be part of larger areas meeting at the Alps. A tentative and cautious interpretation could involve a decrease in moisture supply in winter from the Atlantic and an increase from the Mediterranean. The distribution of precipitation changes in summer are difficult to interpret.

(10) Interpreting the precipitation changes one should keep in mind that the performance of the MLR models is not satisfactory in summer and further that it showed considerable performance reduction in Expts B and C.

Table 4. Regional response to the IS92a-'greenhouse gas plus sulphate aerosol'-scenario relative to the 1961-1995 climatology. Related seasonal statistics of the variables considered in this study winter (DJF), spring (MAM), summer (JJA) and autumn (SON)

\begin{tabular}{|lcccr|}
\hline \multirow{2}{*}{$0.1^{\circ} \mathrm{C}$} & \multicolumn{4}{c}{ Temperature $\left(\mathrm{SO}_{4}\right.$-Exp.) } \\
& DJF & MAM & JJA & SON \\
\hline Min & 18.1 & 20.9 & 11.2 & 14.8 \\
Max & 28.4 & 29.0 & 23.1 & 26.4 \\
Mean & 22.6 & 24.6 & 16.0 & 18.6 \\
SD & 17.8 & 17.5 & 8.6 & 13.2 \\
\hline \% & \multicolumn{5}{c}{ PJF } & \multicolumn{2}{c}{ MAM } & JJA & SON \\
\hline Min & -21.5 & -25.3 & -29.0 & -21.3 \\
Max & 24.0 & -2.0 & 18.4 & 26.4 \\
Mean & -0.2 & -11.1 & -1.5 & 1.5 \\
SD & 48.3 & 36.6 & 23.0 & 39.6 \\
\hline
\end{tabular}



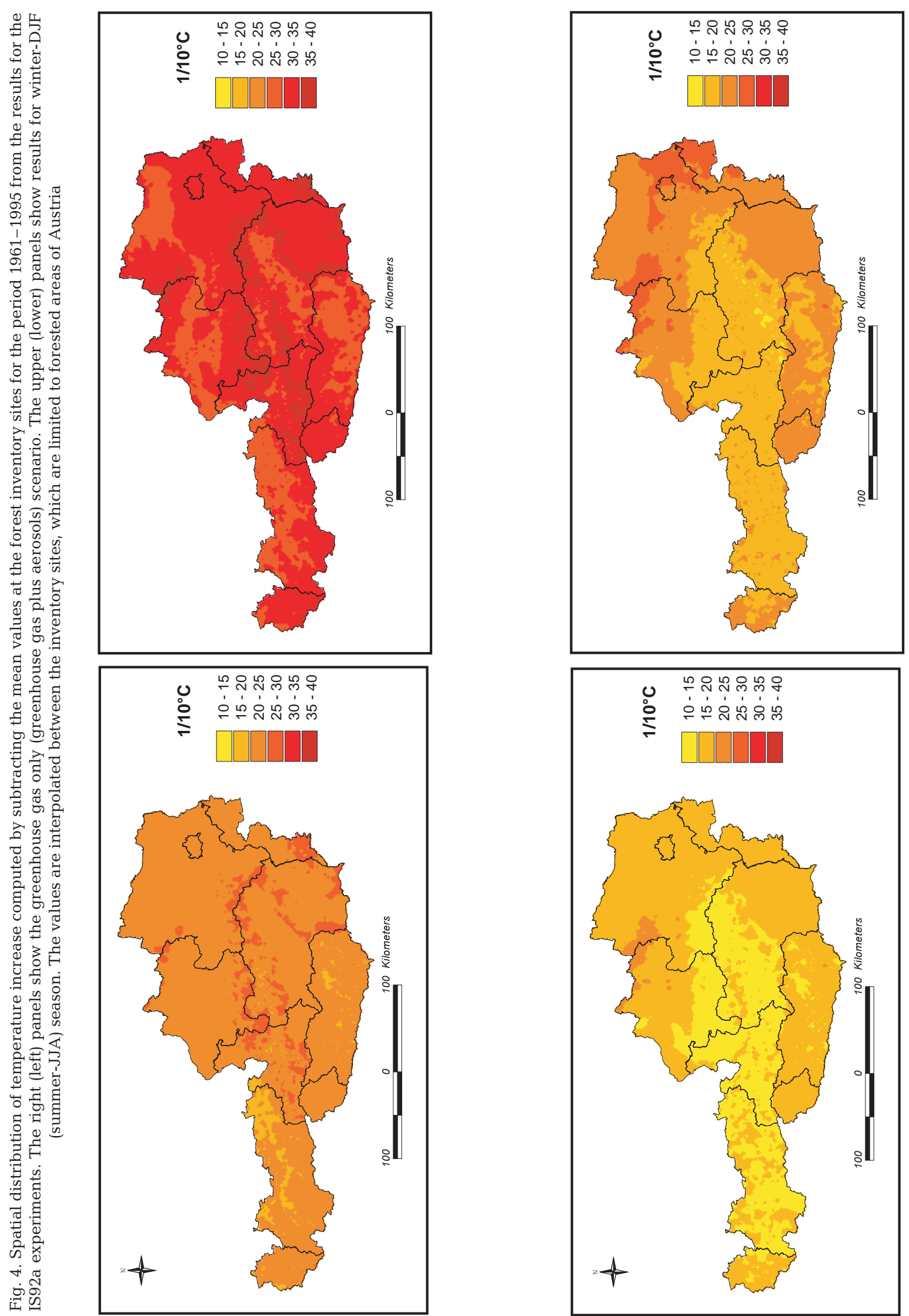

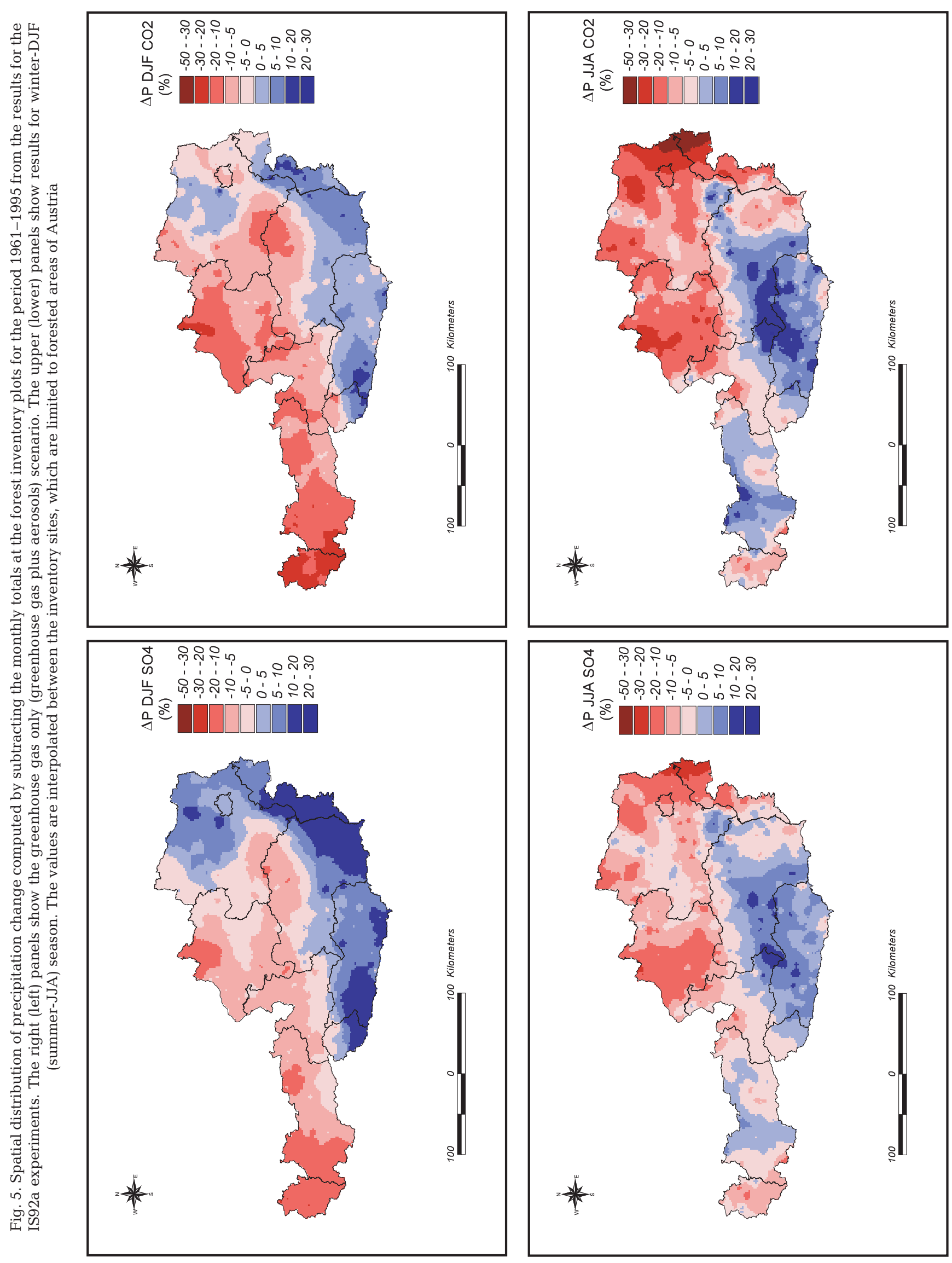


\section{DISCUSSION AND CONCLUSIONS}

In the present work a seasonally stratified statistical downscaling procedure was applied to regionalize output from a GCM for the complex Alpine terrain in Austria. The downscaling experiment was based on about 11000 sample points of the Austrian Forest Inventory. This approach was meant to bridge the gap between the scales of vegetation and soil data on the one hand and of climate change scenario data on the other, thus preparing the ground for spatially explicit regional climate change impact assessments (e.g. Lexer et al. 2000). In general, the results for seasonal mean temperature and precipitation changes are within the expected range. Using the full $35 \mathrm{yr}$ period for model calibration (Expt A) the explained variance ranged from 58 to $91 \%$ for temperature and from 26 to $75 \%$ for precipitation (Table 1). Calibrating the model with the first $25 \mathrm{yr}$ and validating it with the following $10 \mathrm{yr}$ yields explained variabilities in the range of 64 to $92 \%$ for temperature and 0 to $70 \%$ for precipitation for the validation period (Expt B). Dividing the $35 \mathrm{yr}$ period into equal parts for calibration and validation does not influence the validation results in the case of temperature, but reduces the explained variability for precipitation even more. The validation results can be summarized by the following 2 points:

(1) Temperature: the explained variability remains remarkably high. This might indicate that the model achieves good results with a short calibration phase.

(2) Precipitation: from Expt A to B (and further to Expt C) there is a considerable reduction in the model performance. This might indicate that a long fitting period is required and that the fitting period could also be partially affected by the lack of local data and the necessity of the interpolation procedure over a mountain area, where precipitation patterns are complex.

The regionalized IS92a emission scenarios as simulated by ECHAM4/OPYC3 result in an increase of seasonal temperature ranging from +1.4 to $+4.0^{\circ} \mathrm{C}$ (trace gas only integration) and from +1.1 to $+2.9^{\circ} \mathrm{C}$ (trace gas plus sulphate integration) in comparison with the 1961-1995 climatology. This is within the range given by the GCM used.

The regionalized precipitation changes are both negative and positive, and range from -44 to $+26 \%$ (trace gas only integration) and from -29 to $+26 \%$ (trace gas plus sulphate integration) of the 1961-1995 mean values. Temperature and precipitation changes depend not only on the regions but also on the seasonal cycle.

It is well known that the strongly inhomogeneous structure of rain events in space and time makes precipitation forecasts particularly difficult. Especially in summer, small-scale processes driven by convection are responsible for rain events. Weather patterns producing precipitation with a larger temporal and spatial extent are easier to predict. Such large-scale events occur predominantly in winter. As today's GCMs cope quite well with such systems, some authors have restricted precipitation downscaling to the winter months (e.g. Burkhardt 1995, 1999, Dehn 1999). Our results point in the same direction. To provide evidence for this phenomenon we calculated the regression models for precipitation separately for each season and found that the method was performing better in winter than in summer, having a maximum $\mathrm{r}^{2}$ in winter (DJF). These results seem to support the designs of, for example, Gyalistras et al. (1994) and Busuioc et al. (1999) which distinguish between the seasons.

What is the added value of our approach for climate change impact assessments? In the mountainous landscapes of Central Europe soil and weather conditions vary at relatively small scales. Ecosystem response to climate change will therefore not be uniform over larger regions. Thus, it is important for advanced impact assessments to capture the intraregional variability of the interacting effects of soils, current ecosystem structure and composition and climate on the ecosystem response to scenarios of climatic change instead of focusing on regional averages. Regarding forest ecosystems, national forest inventories such as the AFI provide wide spatial coverage at relatively high spatial resolution and allow us to realistically initialise ecosystem models according to the current state of the analysed system. In a recent study, regionalized climate change scenarios from our approach were used to drive a dynamic vegetation model to explore the potential response of Austrian forests under climatic change (Lexer et al. 2001).

In summary the presented approach is promising for statistical downscaling of temperature in Alpine terrain. For precipitation we do not consider it satisfactory, mainly because of the loss of performance in the validation experiment. Continuation of this line of work could include the extention of the time period and a temporally more differentiated approach for model fitting.

Acknowledgements. This study was conducted within the research project 'The Adaption Potential of Austrian Forests to Scenarios of Climate Change' funded by the Federal Ministry of Agriculture and Forestry, the Federal Ministry of Environment, Youth and Family Affairs and the Federal Environmental Agency. We thank the DKRZ and the Zentralanstalt für Meteorologie und Geodynamik, Vienna, for providing data and computer facilities. We would like to thank A. Beck, F. Hamelbeck and especially R. Brunner for fruitful discussions. The paper was improved by the comments of 3 anonymous referees. 


\section{LITERATURE CITED}

Burkhardt U (1995) Validation of the small-scale performance of a climate model. Clim Dyn 11:299-305

Burkhardt U (1999) Alpine precipitation in a tripled $\mathrm{CO}_{2}$-climate. Tellus 51A:289-303

Busuioc A, von Storch H, Schnur R (1999) Verification of GCM-generated regional seasonal precipitation for current climate and of statistical downscaling estimates under changing climate conditions. J Clim 12:258 - 272

Cohen SJ, Allsopp TR (1988) The potential impact of a scenario of $\mathrm{CO}_{2}$ induced climatic change on Ontario, Canada. J Clim 1:669 - 681

Compagnucci R, Salles M (1997) Surface pressure patterns during the year over southern South America. Int J Climatol 17:635-653

Crane RG, Hewitson BC (1998) Doubled $\mathrm{CO}_{2}$ precipitation changes for the Susquehanna Basin: down-scaling from the GENESIS general circulation model. Int J Climatol 18:65-76

Dehn M (1999) Application of an analog downscaling technique to the assessment of future landslide activity - a case study in the Italian Alps. Clim Res 13:103-113

Ehrendorfer M (1987) A regionalization of Austria's precipitation climate using principal component analysis. J Climatol 7:71-89

FBVA (1995) Instruktionen für die Feldarbeit der Österreichischen Waldinventur 1992-1996, Chap 4. Forstliche Bundesversuchanstalt, Vienna, p 194

Fischlin A, Gyalistras D (1997) Assessing impacts of climatic change on forests in the Alps. Global Ecol BioGeogr 6:19-37

Frey-Buness F, Heimann D, Sausen R (1995) A statisticaldynamical downscaling procedure for global climate simulations. Theor Appl Climatol 50:117-131

Fuentes U, Heimann D (1996) Verification of statisticaldynamical downscaling in the Alpine region. Clim Res 7:151-168

Fuentes U, Heimann D (2000) An improved statistical-dynamical downscaling scheme and its application to the Alpine precipitation climatology. Theor Appl Climatol 65: 119-135

Giorgi F (1990) Simulation of regional climate using a limited area model nested in a general circulation model. J Clim 3:941-963

Giorgi F, Shields Brodeur C, Bates GT (1994) Regional climate change scenarios over the United States produced with a nested regional climate model. J Clim 7:375-399

Grotch SL, MacCracken MC (1991) The use of general circulation models to predict regional climatic change. J Clim $4: 286-303$

Gyalistras D, von Storch H, Fischlin A, Beniston M (1994) Linking GCM-simulated climatic changes to ecosystem models: case studies of statistical downscaling in the Alps. Clim Res 4:167-189

Hewitson B, Crane R (1996) Climate downscaling: techniques and application. Clim Res 7:85-95

Hurrell J (1995) Decadal trends in the north atlantic oscillation: regional temperature and precipitation. Science 269:676-679

IPCC (1992) Climate change 1992 - the supplementary report to the IPCC Scientific Assessment. Cambridge University Press, Cambridge

Editorial responsibility: Hans von Storch, Geesthacht, Germany
Joannesson T, Jonsson T, Källen E, Kaas E (1995) Climate change scenarios for the nordic countries. Clim Res 5: 181-195

Kalnay E and 21 others (1996) The NCEP/NCAR reanalysis project. Bull Am Meteorol Soc 77:437-471

Kienast F, Brezeziecki B, Wildi O (1996) Long-term adaptation potential of Central European mountain forests to climate change: a GIS-assisted sensitivity assessment. For Ecol Manage 80:133-153

Lamb P, Peppler R (1987) North Atlantic oscillation: concept and an application. Bull Am Meteorol Soc 68:1218-1225

Lexer MJ, Hönninger K, Scheifinger H, Matulla C, Groll N, Kromp-Kolb H (2000) The sensitivity of central European mountain forests to scenarios of climatic change: methodological frame for a large-scale risk assessment. Silva Fennica 34:113-129

Lexer MJ, Hönninger $\mathrm{K}$, Scheifinger $\mathrm{H}$, Matulla $\mathrm{C}$, and 5 others (2001) The sensitivity of Austrian forests to scenarios of climatic change: a large-scale risk assessment based on a modified gap model and forest inventory data. For Ecol Manage 162(1):53-72

Lindner M, Bugmann $\mathrm{H}$, Lasch $\mathrm{P}$, Flechsig M, Cramer W (1997) Regional impacts of climatic change on forests in the state of Brandenburg, Germany. Agric For Meteorol $84: 123-135$

Lorenz EN (1956) Empirical orthogonal functions and statistic weather prediction Scientific Report No. 1, Contract AF19(604)-1566, Meteorology Department, Massachusetts Institute of Technology, Cambridge, MA

Preisendorfer RW (1988) Principal component analysis in meteorology and oceanography. Elsevier, Seattle

Roeckner E, Oberhuber J, Bacher A, Christoph M, Kirchner I (1996) ENSO variability and atmospheric response in a global coupled atmosphere-ocean GCM. Clim Dyn 12: $737-745$

Scheifinger H, Kromp-Kolb H (1999) Forschungsinitiative gegen das Waldsterben (FIW II); Generalsynopse; Meteorologisches Teilprojekt, Institut für Meteorologie und Physik der Universität für Bodenkultur, Vienna

Smith J (1991) The potential impact of climate change on the Great Lakes. Bull Am Meteorol Soc 72:21 - 28

von Storch H, Zorita E, Cubasch U (1993) Downscaling of global climate change estimates to regional scales: An application to Iberian rainfall in wintertime. J Clim 6:1161 $-1171$

Wanner H, Rickli R, Salvisberg E, Schmutz C, Schüepp M (1997) Global climate change and variability and its influence on alpine climate - concepts and observations. Theor Appl Climatol 58:221-243

Widmann ML (1996) Mesoscale variability and long-term trends of Alpine precipitation and their relation to the synoptic-scale flow. PhD thesis, ETH, Zürich

Wigley TML, Jones PD, Briffa KR, Smith G (1990) Obtaining sub-grid-scale information from coarse-resolution general circulation model output. J Geophys Res 95: 1943-1953

Yarnal B (1993) Synoptic climatology in environmental analysis. Studies in climatology series. Belhaven Press, London

Zorita E, Hughes JP, Lettemaier DP, von Storch H (1995) Stochastic characterization of regional circulation patterns for climate model diagnosis and estimation of local precipitation. J Clim 8:1023-1042

Submitted: March 7, 2001; Accepted: January 4, 2002

Proofs received from author(s): July 18, 2002 